\title{
Agency in the context of social death: Dying alone at home
}

Caswell, G. and O'Connor, M.

\begin{abstract}
Each year a number of bodies are found of people who have died alone at home and whose absence from daily life has not been noticed. Media reports tend either to cast these individuals as deviant, or wider society as having abandoned them to a lonely death. This paper proposes an alternative view, one in which some individuals choose to withdraw from society and enter a period of social death prior to their biological deaths. They may then be subject to a renewed social life after death, brought about through post-death social processes. The paper begins by laying out the background to the pilot study on which it draws, before discussing some of the methodological and ethical issues involved in carrying out such research. A case study is then presented as a focus for a discussion of the possible role of agency and choice within the context of social death.
\end{abstract}

Keywords: agency, dying alone, social death, lone death, found dead, post-death identity

\section{Introduction}

This paper argues that a number of people who live alone make the decision to withdraw from social contact with others and thus enter a self-imposed period of social death prior to their biological deaths. In doing so they are exhibiting agency and creating identities for themselves that are based in personal choice, in accordance with the late-modern project (Giddens, 1991). Occasionally such life choices will result in the death of the individual taking place in circumstances where their body is not found for some considerable time, and societal responses when this occurs indicate that the life choices made by that person when alive are not considered legitimate (Bauman, 2005). There are consequences for the deceased individual who lived and died alone, in that the socially perceived illegitimacy of their life choices may result in their lives and deaths being investigated and their identities recast after death in a form of social life revival (Langer, Scourfield \& Fincham, 2008). This paper makes use of a case study, drawn from pilot research, to explore how this may occur. 
The paper begins by discussing social death and how the concept is used, before going on to consider dying alone and what is already known. The situation where an individual who lived alone has died whilst alone and their body has not been found for an extended period of time will be described here as a lone death; this is for the sake of brevity and clarity of meaning. There will be a brief description of some of the methodological and ethical issues involved in conducting the research upon which the paper is based and the different sources of data used will be discussed. A case study will then be presented which highlights the issues for discussion. It will be argued that Adam Jackson ${ }^{1}$, who features in the case study, chose to enter a stage of social death by withdrawing from social contact with others whilst still biologically alive. After his death, however, Mr Jackson was subject to processes which revived his social life, with no input from him and without consideration to his wishes. $\mathrm{Mr}$ Jackson exhibited agency during his life time, but lost the power to exercise choice after undergoing a lone death.

\section{Background}

\section{Social death}

Social death, as the term is used in this paper, is a process or state in which an individual ceases to be an active participant in the social worlds of others, and the key feature of this conceptualisation of social death is ' ...the cessation of the individual person as an active agent in others' lives' (Mulkay \& Ernst, 1991, 178). It may be that the individual concerned has been judged as close to clinical death by medical professionals, and is then treated as if already dead by healthcare staff and sometimes also by their family and friends (Glaser \& Strauss, 1965; Sudnow, 1967). It may also be the case that the person shows signs that are interpreted by others as indicating membership of a group which is deemed to be moving towards biological death (Hallam, Hockey \& Howarth, 1999). This latter group may include people with dementia, or people who appear frail and old; its constitution depends upon place, time and social context. In both these cases the individuals who are cast as socially dead cease to be active agents in the social lives of others and are treated by others as if they are of no consequence and already dead (Mulkay \& Ernst, 1991).

\footnotetext{
${ }^{1}$ The names Adam Jackson, Oliver and John, which are used in this paper, are pseudonyms. Small details about Adam Jackson have also been changed in order to protect his anonymity, whilst not affecting the analytical significance of the data presented.
} 
It is not sufficient to say that all people with dementia, or all those who appear to be frail and elderly, are also socially dead. There are many people in these groups who continue to be socially significant in the lives of others. It is the case, however, that an individual may be cast as socially dead by some people and therefore not be considered as players in their social lives, but that same individual may feature prominently in the social plans and lives of others (Mulkay \& Ernst, 1991). For example, an older person with dementia may be deemed of no social consequence by some members of their family and thus be socially dead to those family members, but they may simultaneously have an active 'social presence' amongst their peers (Hallam et al. 1999, 45). Some individuals, therefore, move in and out of periods of social death and social life and may at times be cast as socially dead and other times as socially alive.

Linked with the notion of simultaneous social death and biological life is the idea of an ongoing social life that comes after biological death. In the immediate aftermath of a death bereaved individuals may continue to interact with the person who has died, holding their hand, talking to and reassuring them (Hallam et al. 1999; Mulkay \& Ernst, 1991). Such a social existence after biological death is not restricted to the period immediately after death, however, and for many who have been bereaved the deceased person remains an important part of their lives and everyday considerations. Bereaved people may think about the person who has died, talk to them, ask their advice and consider their feelings over an extended period of time (Valentine, 2008). As is the case with social death that occurs prior to biological death, an ongoing social life for someone who is already dead may occur in some of their relationships but not in others. A widow, for example, may continue to keep her dead husband socially alive and maintain an ongoing bond with him, while her children may not have such a relationship with their dead father (Walter, 1999).

One important factor in these accounts of social death while the individual is biologically alive, and social life when the individual is biologically dead, is that the status is usually conferred upon the individual by other people. When this happens it is often a case of society's younger members imposing the status on older people, implying that the older individual has no choice in the matter (Hallam et al. 1999). This paper, however, suggests that for some people this may not be the case; for a possibly small heterogeneous group of people the decision to enter a phase of social death is one that they make for themselves. The possibility that an individual may choose social death presupposes the existence of agency, of a social actor who is able to make independent decisions and enact them. The exercise of 
agency is grounded within the '...structures and processes of the human self, conceived of as an internal conversation...' (Emirbayer \& Mische, 1998, 974); the individual has social relationships with other people and with themselves and is able to consider their options, make choices and act upon those choices.

The exercise of agency, however, does not take place in a vacuum. All individuals, including those who have little contact with others, live within a social context which influences not only the choices that they make, but also the options on which they draw when making those choices. Such influences may be in the nature of structural constraints or opportunities; for example, social class positioning at birth may provide one individual with an education which opens up a range of possibilities for success in later life, whilst for another individual his or her social class and consequent educational opportunities may limit options for the future (Giddens, 1991). The relational context within which people live may also be a source of either opportunity or constraint (Gardiner, et al., 2009). Living within a supportive network of family and friends may offer a suitable milieu for an individual to utilise opportunities, while the lack of such a network may leave another individual bereft of opportunities and aware only of constraints. People living alone are not immune to the influences of the social context within which they live, and the decisions that they make about their lives are subject to the operation of constraining and enabling factors, as are the lives of all society's members (Giddens, 1991).

For some individuals one of the choices they make will include the decision to live alone. When this is the case there is the possibility that they will die biologically while alone at home and their body will not be found until sometime later, representing what has been termed a kind of 'abandonment' (Seale, 1995, 376). This may be particularly likely for individuals who have entered a period of social death, and it may hold consequences for their status as socially living individuals after death.

\section{Dying alone}

Every year unknown numbers of people who ordinarily live alone die alone at home and their bodies are found sometime later, undergoing what is described here as a lone death. Such deaths are in contrast to what are usually described as 'good deaths' which typically involve emotional accompaniment, a suitable physical environment, supportive care from health care 
professionals and attention to spiritual needs (for discussion of these issues see, for example, Borbasi, Wotton, Redden \& Chapman, 2005; Cipolletta \& Oprandi, 2014; Hart, Sainsbury \& Short, 1998; Masson, 2002). Occasionally the period between death and the finding of the body will be months, or even years. When this occurs, it results in media interest and headlines asking questions about the nature of contemporary society and the manner in which social relationships have changed. ${ }^{2}$ In most cases, however, the period between the individual dying and their body being found is likely to be short, and a matter of hours or days is unlikely to cause even a ripple beyond the environs in which the death took place. The numbers of people living alone are increasing in countries such as the United Kingdom (UK) and the United States of America (Jamieson \& Simpson, 2013; Klinenberg, 2012). In 2014 there were 7.6 million people living in single person households in the UK (Office for National Statistics, 2015). There are 11 million people aged 65 and over in the UK, of whom 3.8 million, or 36 percent, live alone. Of this older group survey findings suggest that 49 percent rely on the television or pets as their main form of social contact, and that 11 percent have less than monthly contact with other people in the form of family, friends or neighbours (Age UK, 2015).

Approximately 90 percent of UK deaths are of people aged over 65 (Age UK, 2015), therefore deaths alone at home are most likely to occur amongst this age group. ${ }^{3}$ There is little research evidence regarding the views of people living alone about how and where they would wish to die. Survey evidence suggests that between 40 and 50 percent of people who are terminally ill and who live alone may prefer to die at home (Aoun \& Skett, 2013), but understanding the views of individuals who live alone is not straightforward as they may be influenced by a variety of factors. Such influences may include the belief that they are not allowed to stay at home as they are dying, they may have concerns about the quality of care available and about professionals entering the private space of their home, and they may also experience a fear of dying suddenly and alone (Gott et al, 2004; Lloyd-Williams et al, 2007).

Some individuals living alone may choose to remain alone despite the risk of a lone death, while others may not care one way or the other (Howse, 1997; Kellehear, 2009). Although

\footnotetext{
${ }^{2}$ See, for example, http://www.dailymail.co.uk/news/article-1197314/Woman-85-laydead-flat-years-noticed-missing.html or Coroner's concern at increase in "old and alone" deaths: http://www.bbc.co.uk/news/uk-wales-11526737

${ }^{3}$ Such deaths are not exclusive to older people. See, for example, the case of Joyce Carol Vincent who was 38 when she died alone and whose body was not found for three years: http://www.theguardian.com/film/2011/oct/09/joyce-vincent-death-mysterydocumentary
} 
lone deaths have been described in terms redolent of a lack of social contact, there is little evidence as to whether those who live alone prior to their deaths undergo a period of social death. Howse, in his study of the coroner records of 647 lone deaths of older people in Southwark and Waltham, used the terms isolation, loneliness and abandonment in his report, while acknowledging that there may be an element of choice in an individual's being alone as they approach death (Howse, 1997, 24, 43-46). An earlier study categorised the individuals who underwent a lone death as reclusive, reserved, independent or sociable and came to the conclusion that while such deaths may have been contrary to expectations in the 1960s and 1970s, for some older people living and dying alone may have been a valid choice (Bradshaw, Clifton \& Kennedy, 1978, 15, 23-24).

The research evidence is therefore not vast, but suggests that some individuals who live alone make an active decision to stay at home alone as they are dying and that their lone deaths may be the result of their exercise of 'agency, resistance and dissent' (Kellehear, 2009, 5). It is also possible that some people who live alone may choose to withdraw from social contact and impose upon themselves a form of social death, prior to their biological deaths. The paper will now turn to a consideration of the research upon which it draws.

\section{The research}

\section{Methodological choices}

The case study on which this paper draws comes from a pilot study which aims to explore the phenomenon of lone deaths and to tease out the most appropriate ways in which this subject can be researched. Two approaches have been used. One is to recruit individuals who live alone and to explore with them their views on how they would wish to be cared for - if they wish to access care services - as they approach the end of their lives, and their views on the possibility of dying alone. The second approach has been to test the sociological autopsy as a methodology for retrospectively exploring the phenomenon of dying alone at home. This latter phase of the study is drawn upon here. It involved examining deaths which had already occurred using coroner records as a starting point, in an effort to gain some understanding of the social circumstances in which the individual lived, and then died, alone.

This methodological choice was inspired by suicide research which made an ethnographic study of coroner case files. The ethnographic approach to the study of documents required 
consideration of 'documents as objects of study' whilst simultaneously using the coroner files to study cases of suicide (Langer et al., 2008, 295). The classification of a death as suicide in England and Wales is made after an investigation and an inquest, held under the authority of the coroner, making the coroner files a logical starting point for exploring suicide. The researchers examined 100 coroner case files, which they discovered to contain a variety of artefacts, including the coroner's certificate, medical and autopsy reports, witness statements, suicide notes, police reports and photographs (Langer et al., 2008). It was not clear how useful such records would be as a way to begin the investigation of lone deaths. The office of coroner in England and Wales is a unique one. The post holder may be either medically or legally qualified ${ }^{4}$ and the role involves conducting an investigation into sudden, suspicious or unexplained deaths in order to establish the cause of death, the identity of the deceased person and whether the death was from natural or unnatural causes. The coroner has the power to order a post-mortem examination and the authority to hold an inquest, which is a public hearing to investigate the circumstances of a particular death (Dorries, 2004).

For this study there were issues to resolve about how to identify individuals who had lived and died alone at home. Although place of death is recorded, whether or not a person died alone at home is not a category for which statistics are generated, either for the Coroners' Service or the Office for National Statistics ${ }^{5}$, unlike cause of death or the decisional outcome of an inquest. In addition, researchers do not have automatic access to coroner records unlike those, such as relatives of the deceased, who are deemed to be 'properly interested persons' (Dorries, 2004, 304, 307). Furthermore, coroners are independent judicial officers who are appointed by local authorities, so that each coroner will decide for him or herself whether or not access should be given to a researcher (Coroners' Society a, nd). Access is reported as more likely to be given to researchers who can provide names and dates of death (Coroners' Society $b$, nd), so there was a need to pre-identify individuals of interest to the research before approaching the appropriate coroner's office.

\footnotetext{
${ }^{4}$ There are changes underway under the Coroner and Justice Act 2009, and information about this can be found on the Coroners' Society of England and Wales website here: http://www.coronersociety.org.uk/becoming a coroner ${ }^{5}$ The Office for National Statistics, or ONS, is the body which produces official statistics for the UK on the economy, population and society: http://www.ons.gov.uk/ons/aboutons/index.html
} 


\section{Ethical considerations}

Conducting research that involves human participants brings with it ethical issues that need to be addressed, and research about topics that are viewed as sensitive, such as dying and death, presents extra challenges (Lee, 1993). In setting up this study there was a particular concern about involving people who had died before the research began and the impossibility of their having any choice about participation. There are differing philosophical perspectives as to whether or not those who are dead can be harmed (Tomasini, 2008; Wilkinson, 2002; Wisnewski, 2009), and it is unlikely that any of the deceased individuals who are of interest to the research will have anyone to speak for them. Researchers dealt with this dilemma by changing the names of the individuals and their locations in order to protect their anonymity. However, researchers are aware that this is a compromise and that involving those individuals who have undergone lone deaths in the research risks rewriting their identities as social beings post-death in ways that the individual may not have found acceptable. This will be discussed further below.

\section{Data generation}

A case study approach was selected as the most appropriate way to generate and present indepth data, and four cases from three different coroner offices were included in the pilot. The desire was to explore individual cases of lone deaths, comparing and contrasting in an effort to understand both similarities and differences (Yin, 2009). Data is presented here from one case study, selected for the variety of data sources upon which it is based and the differences in their approach to the case. The case study is that of Adam Jackson, and the data drawn upon about his life and death come from three different sources: the coroner record about his death, reports in the local press about his death and the inquest, and a research interview with Oliver, a work colleague of Adam Jackson's. These data sources differ from each other. Two are documentary, written for purposes other than research and in different contexts (Prior, 2003). The third data source was an interview in which Oliver who shared with the interviewer his memories, perceptions and interpretations of Mr Jackson's beliefs and behaviour.

Coroner records proved to be a rich starting point for data on lone deaths. The coroner's record of the inquiry and the inquest into the death of Adam Jackson were focused on the fact 
that there had been an unexplained death, that the identity of the person who had died needed to be established and that the cause of death needed to be ascertained. In going about its legally constituted business the coroner's office created a narrative about the dying of Adam Jackson, using specially crafted documents such as police reports, witness statements, a postmortem report, a GP letter and the coroner's verdict. The language used by the coroner is measured, medical and technical; it is not intended to be emotional and it is produced as an account of the facts which are interpreted in a scientific manner (Langer et al. 2008; Prior, 1989).

The media coverage of the death of Adam Jackson was written from a different perspective and with a different purpose to that of the coroner record. The role of the news media is to discover fresh information that is of interest to the public, and to convey it to them as quickly and accurately as possible; at its best the reporting of such news will be balanced and honest. There are, however, many other considerations in what is constituted as news and how it is presented (Cole \& Harcup, 2009). Adam Jackson's death was reported in the newspaper covering the locality in which he lived. The coverage was largely focused on reporting the inquest and the views of people who had reason to be interested in the local area. If the report of the inquest is excluded, the views of 14 individuals were reported in the press, but only two had known Adam Jackson when he was alive. Unlike the language in the coroner record, the language used in the press was emotive and designed to prompt a reaction, thus helping to shape the opinions of those who read the stories about lone deaths in general and the death of Adam Jackson in particular (Tuchman, 1978).

Each data source used in this case study required cautious handling during analysis. None offers direct access to Adam Jackson, his life and actions, but instead each source offers an interpretation borne out of a particular purpose and context. In consequence the case study presented below suggests an approach to life that may have been taken by Adam Jackson, drawing on all three data sources.

\section{Case study: Adam Jackson}

Adam Jackson was born in the mid-1940s in a medium-sized English city. He was an only child and his parents owned the house in which the family lived; Adam himself never married nor did he have children. His father was a self-employed carpenter and when Adam left 
school he went to work for his father. After his father died in 1972, Adam and his mother continued to live in the same house, but Adam worked for a firm of builders in the city. Adam's mother died in the early 1990s, and soon after that he retired from work when he was in his late $40 \mathrm{~s}$.

Adam Jackson continued to live in the family home. An ex-colleague, John, who gave evidence at the inquest, described Adam as 'a little strange, not in a frightening way, but in an autistic-type way.' John gave evidence that after Adam retired, 'I didn't have much contact with him. I just used to see him in the street... once or twice a year.' The last time John saw Adam was, he thought, during the winter of 2009 to 2010 when he had seen him in the queue at the bank.

Another ex-colleague, Oliver, was interviewed as part of the research project. He agreed that Adam Jackson was different, but thought that he had neither autistic tendencies nor any form of mental illness:

I don't think he had mental illness, I think it was just the demeanour that he had. I mean if you want to define being... a recluse as being a mental illness then yes he did. But if you don't, then he didn't...he wasn't normal, but he wasn't so abnormal.

Adam kept up to date with the news and was able to converse on most topics, but he rarely started a conversation. Oliver said that he and his colleagues:

All knew he (Adam) was a private bloke ...like the shutters went down with him. You could have a conversation, he was quite well read and he was up to date with current affairs...he was just a regular bloke...he was a hard worker, worked well with other people and on his own.

Adam Jackson retired after the death of his mother, but Oliver was unsure whether this was because he no longer needed the income that work provided or because it had been Adam's mother who insisted he went out to work. As far as Oliver was aware, Adam only knew about half a dozen people, from the time when he had worked in the construction firm. Although Oliver and some other colleagues predicted the end that Adam might come to, they knew that he would not have liked them visiting him just to keep an eye on him, so they did not do so. Oliver said: 
we worried at the time whether this would be his end... because so few people knew (him), I don't think he'd got a telephone or mobile, he never had visitors, we never went round to his house, you'd see him shopping in town now and again, but the thought was if anything happens to him, nobody's going to know. Nobody's going to miss him, when you do see him, it's oh, there's Adam not, where's Adam?

In Oliver's view it was not the case that society had forgotten Adam Jackson, but rather that Adam Jackson had removed himself from society. Oliver said:

He was happy living on his own. When you saw him in town it was just a nod... any more would have been an intrusion... he was just a nice guy who wanted to be left alone...he just blended into the background, that was the life he led and ultimately the death that he had.

In so far as the manner of his death was concerned, Oliver felt that Adam would not have been worried about it, and Oliver believed that it was an achievement on Adam's part that he could live his life in the manner he chose for himself:

It's not shocking that he died alone and wasn't found for four years, because he lived alone for 20 years before that and wasn't noticed...I think he died alone, but he wasn't lonely... I actually think it's a little bit of a triumph for the individual against the system ...Adam lived for almost 70 years and in that time managed to keep off loads and loads of databases to the point where you can die and not be missed for four years...it's nice that if somebody wants to do that they can still do it in the $21^{\text {st }}$ century...he just lived a very quiet, very simple personal life and I think for the vast majority of it he was happy...I think it's a credit to him that he's been able to do that.

Adam Jackson's dead body was found in his home in the spring of 2014 when a bailiff attended the house because of unpaid bills. His body was largely skeletonised, with no internal organs remaining, and the pathologist who carried out the post-mortem on behalf of the coroner presumed that the body was that of Adam Jackson. The pathologist concluded that 'no cause of death can be given' as decomposition was too advanced. As Adam Jackson had not visited his general practitioner since 2003 it was not known whether he had any medical condition that might have contributed to his death. 
The police investigation found no one living nearby who knew Adam Jackson. His home was in a short terrace of houses, but the property on one side was empty and the house on the other side was occupied by several short-term tenants. The house was secure when $\mathrm{Mr}$ Jackson was found and there were no signs of a struggle. The police report included in the coroner's file stated:

The property is an absolute mess...Tons and tons of alcohol bottles strewn across the floor and no room to walk through. Loads of undisturbed cobwebs draped across doorways...would appear no one been in the address for a very long time.

The police officer concluded that Adam Jackson 'may have been an alcoholic.' Indications in the house, from the use-by dates on food and publication dates on newspapers, suggested that Adam Jackson had been alive at the end of 2010. The coroner recorded an open conclusion when the inquest was closed in November 2014, as there was insufficient evidence to assign a cause of death (Dorries, 2004).

In the spring of 2014 the coroner issued a cremation certificate, permitting the registration of the death and the disposal of the body. As the police had been unable to find any relatives the local authority organised the funeral, using a local firm of funeral directors. At a later date council workers emptied the house of Adam Jackson's belongings, clearing away the last signs of his life and death.

Local media coverage of Adam Jackson's death was mainly focused on the period subsequent to the inquest. Mr Jackson was described as 'forgotten', his death a 'sad sign of our times' and 'a sad example of modern society'. His story was 'tragic' and the question was asked as to whether his death was 'a sad indictment of society today?' Adam Jackson's home and the surrounding area were described in graphic detail, setting the scene for readers of an area with a transient population and derelict buildings in the midst of which Adam Jackson lived in a house with dirty windows and closed curtains. There were photographs of the house included in the coverage, appearing unkempt and semi-derelict, but there were no pictures of Adam Jackson himself. The newspaper reporter spoke to local councillors, representatives of an organisation that works with older people and the Member of Parliament for the constituency, plus local traders and people who lived in the vicinity. Their reported comments all focused on Adam Jackson as a victim who had no control over the 
circumstances of his life and death and for whom readers should feel sad and perhaps a little guilty.

Oliver, however, felt that the coverage of Adam Jackson's life and death in the local press was unfair, because:

What seemed to be missed in the papers was that although he'd been dead four years when he was found, he'd been alive for 60 odd before that and functioned quite well. He'd had a job, he'd made his own decisions and he'd managed his life... between leaving (the firm) and dying he bothered nobody, nobody bothered him.

\section{Discussion}

Data generated in the course of research does not give direct access to reality, and must always be handled with caution (Hughes and Sharrock, 1997). In this case we do not have access to Adam Jackson's own thoughts and perspective, and have no way of assessing the influence that the death of his mother may have had on his decision-making processes, or how a possible problem with alcohol may have affected his life. As already noted, the data sources on which the paper does draw must be handled with care. The Coroner's record and the newspaper reports were written for specific purposes, and Oliver may have been concerned to maintain his 'moral reputation' in his evaluation of Adam Jackson's life and death (Seale, 1995, 376).

\section{Choosing social death}

Inquest evidence given by John and research interview data generated from Oliver suggest that Adam Jackson chose to retire when he did and from that point on he had little contact with other people. Oliver further suggests that Adam lived the life of his own choosing, making the decision to withdraw from society so that rather than society forgetting about Adam Jackson he was the one who elected to forgo society. It certainly appears that Adam Jackson went out into the city in which he lived, for example newspapers were brought into the house, which do not appear to have been delivered by a newsagent, and groceries were found in the house which must have been purchased. However, it also seems to be the case 
that he was not noticed. In the summary of the case the coroner noted that 'he had not been seen alive for many years', but a more accurate rendering of the situation may be that Adam Jackson went out in order to supply his needs but in doing so was not noticed by other people; as Oliver expressed it, 'he just blended into the background'. This is suggestive, although by no means conclusive, of Adam Jackson deciding to withdraw from social contacts in the period preceding his biological death and thus entering a state of social death in which he impinged on the social life of no one else (Mulkay \& Ernst, 1991). As an active agent it appears likely that Adam Jackson chose social death.

Choosing social death resulted in Adam Jackson living, and then dying, in a situation which is not accepted as legitimate by the society of which he was part. Such a death is often interpreted as a failure on the part of society, of relatives, of neighbours and friends, and it presents a picture of a lonely older person who has been abandoned and rejected by other people (Kellehear, 2009; Seale, 1995). Such an interpretation negates the individual's agency and the power they held to make their own decisions, casting them as victims of life and loneliness; but it is not the case that all those who are alone are necessarily lonely (Kellehear, 2009). The media coverage of Adam Jackson's death portrayed exactly such a lonely life and death, as an older person whom society forgot. Considering the broader set of evidence, however, it appears that Mr Jackson may have been one of the individuals to whom Kellehear refers when he describes those who choose to live and die alone as a means of exercising 'agency, resistance and dissent' (Kellehear, 2009, 5).

\section{Rejuvenated social life after death}

When an individual chooses social death above social life whilst still biologically alive there are a number of possible consequences that come with this decision. In the case of Adam Jackson these consequences came into being after he had died and once his body was found. The late-modern project offers individuals the opportunity to create their own identities, choosing who they wish to be from a range of bespoke options. There are limitations to the identities that an individual can take on, and these limitations are frequently linked to social and economic positioning within a social setting (Giddens, 1991). A social setting which

prizes individual identity creation may be expected to appreciate unusual identities and those who are eccentric, but this is not necessarily the case. Eccentricity and difference require to be retained within certain boundaries in order to be understood and appreciated, so that 
individuals experience the pressure to be simultaneously both different and ordinary (Bauman, 2005).

Adam Jackson chose to be different in a way which is not accepted as legitimate by the society within which he lived. After he died there were legal and social processes put into practice which endeavoured to rewrite his identity in ways which would make him comprehensible to wider society. This process began once his body was found and his death had been reported to the coroner. The job of the coroner and their team was to discover who had died, when and how the death had taken place and whether there were any suspicious circumstances to the death. Once these questions were answered the death could be certificated and registered and Adam Jackson could be entered into the statistics, as gathered by the Office for National Statistics. In this, however, Mr Jackson largely defeated the system. The pathologist was unable, because of the advanced state of decomposition, to assign a definitive cause of death and was also unable to say when death had occurred. Adam Jackson had never been arrested by the police so neither his fingerprints nor his DNA ${ }^{6}$ were on record for comparisons to be made, and in addition his teeth were in good condition so that he had never attended a dentist and it was not possible to compare his dental records with those of the dead body.

The coroner wrote that, 'The house was secure when he was found and there was no evidence of any third party involvement, nor evidence that he had taken his own life.' The coroner and the police officers who carried out the investigation were satisfied that the dead man was Adam Jackson, but could not categorically state this to be the case; it was presumed rather than known. At the end of the inquest the coroner reached an open conclusion which is the appropriate response when the evidence available 'does not fully or further disclose the means whereby the cause of death arose' (Dorries, 2004, 272). The coroner failed to find a good fit between Adam Jackson's life and death, and the categories into which those who die in England and Wales are supposed to be placed. The death of Adam Jackson is therefore cast as an open conclusion, the repository for those whose deaths do not fit into neat classifications.

\footnotetext{
${ }^{6}$ Deoxyribonucleic acid (DNA), genetic material that makes each species and individual within the species unique. Often used in criminal investigation to identify perpetrators: https://www.gov.uk/government/uploads/system/uploads/attachment data/file/252885/NDNAD Annual Report 2012-13.pdf
} 
The media were less circumspect in the way they treated Adam Jackson after his death. There appeared to be no question that the body was that of Adam Jackson, and the reports showed no hesitation in rewriting his identity from that of an individual who made unusual choices in his life to an individual who had no control over his life and death. This rewritten Adam Jackson was portrayed as a victim of tragic circumstance who had been abandoned by society. He had been a reclusive drinker who had preserved his mother's bedroom as it had been when she died during the 1990s, with the implication that he had struggled and been unable to cope on his own. Such a media construction of someone who has died alone is not unusual, making moral judgements on those involved in a particular case and identifying the deceased person as having character flaws which contributed to them dying alone in a way that is constructed as undesirable. In this way the writer of such a piece can '...position themselves as bearers of moral messages and guardians of the community, aligned with official morality about how such a society ought to behave' (Seale, 2004, 973).

What the coroner record and the media coverage have also accomplished in the case of Adam Jackson is to create new social identities for him beyond his death. The coroner has established an identity for him as someone whose death was unexplained and therefore subject to inquiry. In the act of conducting this inquiry and holding an inquest Adam Jackson has been brought into the public eye and has been subjected to what appears to have been against the wishes of the living man, that is, he has been noticed by other people. The media coverage has created an identity for Adam Jackson as a sad, tragic, lonely man who was abandoned by society and who could not cope with life without alcohol (Langer et al. 2008). Thus the late-modern project of identity creation has been turned against a man who in life built himself an identity based on agency and independence, and it has been used to re-create an identity for Adam Jackson after his death, in an effort to make him socially understandable and acceptable (Bauman, 2005; Giddens, 1991).

The research into which Adam Jackson has been drawn without his permission is also not without responsibility in causing him to have a social life after his death. Reading, thinking and writing about him, as well as talking to Oliver about him during interview have all contributed to processes whereby the memory of Mr Jackson continues. While there is no reason to assume that we know what he would have thought of this, the man described by Oliver would have been unlikely to come forward voluntarily to participate in research. Of his inclusion in research Oliver said: 
I don't think he'd have appreciated the press coverage because it throws him into the limelight that he really didn't want, but just discussing and sort of, I don't know, we' re sort of validating his existence. I don't think he wouldn't have appreciated that...I don't think he'd have minded, although I don't think he'd have volunteered...his backstory is worth recording, it's important, but it's not the tragedy that the papers made it out to be...if he was alive now nobody still would have heard of him.

\section{Conclusion}

Evidence suggests that Adam Jackson may have chosen social death for himself while he was still alive, but that social life was chosen for him after his death by the processes that are an integral part of the English social and legal fabric. As an active social agent, Adam Jackson created his own identity, but he did so in a form that was not recognised within the social setting in which he lived. Adam Jackson was one man, and it is unknown how many others may be in a similar position to that which he occupied, opting for a form of social withdrawal and death whilst living, rather than having it imposed upon them. The pilot study upon which this paper draws was designed to test the most appropriate way in which to explore the phenomenon of the lone death. Findings suggest that coroners' case files make a good starting point offering, as they do, the possibility of further avenues of exploration beyond the documents contained in the file. Adam Jackson's story highlights a need to search for greater understanding and for differentiating between those who yearn for company as they are living and dying and those who prefer to be alone. However, his story is suggestive rather than conclusive, and the expansion of the research to encompass an examination of other lone deaths would help to promote the understanding that for some individuals living and dying entirely alone is a legitimate choice.

Individuals such as Adam Jackson eschew health and social care services, perhaps from a perception that engagement with services will bring a level of unwanted intrusion, or a forced move from home (Gott et al., 2004). Greater appreciation of the legitimacy of individuals' choices could inform the development of services that are appropriate to their needs and wishes. The British ideal 'good death', as reflected in end-of-life care policy, occurs at home, but to die alone is 'bad', even though many lone deaths are likely to be at home. Rather than 
being a contradiction in ideals, this paper suggests that, in some cases, the two are compatible; for some, dying alone at home may be acceptable.

\section{References}

Age UK (2015) . Later life in the United Kingdom February 2015. Retrieved from http://www.ageuk.org.uk/Documents/EN-

GB/Factsheets/Later_Life_UK_factsheet.pdf?dtrk=true

Aoun, S.M., \& Skett, K. (2013). A longitudinal study of end-of-life preferences of terminallyill people who live alone. Health and Social Care in the Community, 21, 530-535.

Bauman, Z. (2005). Liquid life. Cambridge: Polity Press.

Borbasi, S., Wotton, K., Redden, M. \& Chapman, Y. (2005). 'Letting go: a qualitative study of acute care and community nurses' perceptions of a 'good' versus a 'bad' death', Australian Critical Care, 18(3), 104-113.

Bradshaw, J., Clifton, M., \& Kennedy, J. (1978). Found dead: a study of old people found dead. London: Age Concern.

Cipolletta, S. \& Oprandi, N. (2014). 'What is a good death? Health care professionals' narrations on end-of-life care', Death Studies, 38, 20-27.

Cole, P., \& Harcup, T. (2010). Newspaper journalism. London: Sage.

Coroner's Society of England and Wales (nd, a). Ministry of Justice. Retrieved from http://www.coronersociety.org.uk/ministry of justice

Coroner's Society of England and Wales (nd, b). Research. Retrieved from http://www.coronersociety.org.uk/research

Dorries, C. (2004). Coroners' courts: a guide to law and practice.( $2^{\text {nd }}$ ed.).Oxford: Oxford University Press.

Emirbayer, M., \& Mische, A. (1998). What is agency? The American Journal of Sociology, 103, 962-1023. 
Gardiner, J., Stuart, M., MacKenzie, R., Forde, C., Greenwod, I. \& Perrett, R. (2009). Redundancy as a critical life event: moving on from the Welsh steel industry through career change. Work, employment and society, 23(4), 727-745.

Giddens, A. (1991). Modernity and self-identity. Stanford CA: Stanford University Press.

Glaser, B.G., \& Strauss, A.L. (1965). Awareness of dying. London: Weidenfeld and Nicolson.

Gott, M., Seymour, J., Bellamy, G., Clark, D., \& Ahmedzai, S. (2004). Older people's views about home as a place of care at the end of life. Palliative Medicine, 18, 460-467.

Hallam, E., Hockey J., \& Howarth, G. (1999). Beyond the body: death and social identity. London: Routledge.

Hart, B., Sainsbury, P. \& Short, S. (1998). 'Whose dying? A sociological critique of the 'good death', Mortality, 3(1), 65-77.

Howse, K. (1997). Deaths of people alone. London: Centre for Policy on Ageing and Help the Aged.

Hughes, J. \& Sharrock, W. (1997). The philosophy of social research. (3 ${ }^{\text {rd }}$ ed.). Harlow: Longman.

Jamieson, L., \& Simpson, L. (2013). Living alone. Basingstoke: Palgrave Macmillan.

Kellehear, A. (2009). Dying old - and preferably alone? Agency, resistance and dissent at the end of life. International Journal of Ageing and Later Life, 4(1), 5-21.

Klinenberg, E. (2012). Going solo. New York: The Penguin Press.

Langer, S., Scourfield, J., \& Fincham, B. (2008). Documenting the quick and the dead: a study of suicide case files in a coroner's office. The Sociological Review, 56, 293-308.

Lee, R.M. (1993). Doing research on sensitive topics. London: Sage.

Lloyd-Williams, L., Kennedy, V., Sixsmith, A., \& Sixsmith, J. (2007). Perceptions of people over the age of 80 on issues surrounding death and dying. Journal of Pain and Symptom Management, 34, 60-66. 
Masson, J.D. (2002). 'Non-professional perceptions of 'good death': a study of the views of hospice care patients and relatives of deceased hospice care patients', Mortality, 7(2), 191209.

Mulkay, M.,\& Ernst, J. (1991). The changing profile of social death. European Journal of Sociology, 32, 172-196. Doi: 10.1017/S0003975600006214

Office for National Statistics (2015).Family and households, 2014. Retrieved from http://www.ons.gov.uk/ons/rel/family-demography/families-and-households/2014/familiesand-households-in-the-uk--2014.html

Prior, L. (1989). The social organization of death. Basingstoke: Macmillan.

Prior, L. (2003). Using documents in social research. London: Sage.

Seale, C. (1995). Dying alone. Sociology of Health \& Illness, 17, 376-392.

Seale, C. (2004). Media constructions of dying alone: a form of 'bad death'. Social Science \& Medicine, 58, 967-974.

Sudnow, D. (1967). Passing on The social organization of dying. New Jersey: Prentice-Hall.

Tomasini, F. (2008). Research on the recently dead: an historical and ethical examination. British Medical Bulletin, 85, 7-16.

Tuchman, G. (1978). Making news: a study in the construction of reality. New York: The Free Press.

Valentine, C. (2008). Bereavement narratives. Abingdon: Routledge.

Walter, T. (1999) On bereavement the culture of grief. Maidenhead: Open University Press. Wilkinson, T.M. (2002). Last rights: the ethics of research on the dead. Journal of Applied Philosophy, 19, 31-41.

Wisnewski, J.J. (2009). What we owe the dead. Journal of Applied Philosophy, 26, 54-70.

Yin, R.K. (2009). Case study research. (4 ${ }^{\text {th }}$ ed.). Thousand Oaks, CA: Sage. 
